\title{
Honoré de Balzac, Albert Savarus
}

\section{Marco Stupazzoni}

\section{(2) OpenEdition}

\section{Journals}

\section{Edizione digitale}

URL: https://journals.openedition.org/studifrancesi/21386

DOI: 10.4000/studifrancesi.21386

ISSN: 2421-5856

\section{Editore}

Rosenberg \& Sellier

\section{Edizione cartacea}

Data di pubblicazione: 1 décembre 2019

Paginazione: 584-585

ISSN: 0039-2944

Notizia bibliografica digitale

Marco Stupazzoni, «Honoré de Balzac, Albert Savarus», Studi Francesi [Online], 189 (LXIII | III) | 2019,

online dal 01 mars 2020, consultato il 11 novembre 2021. URL: http://journals.openedition.org/ studifrancesi/21386 ; DOI: https://doi.org/10.4000/studifrancesi.21386

Questo documento è stato generato automaticamente il 11 novembre 2021.

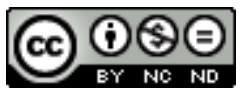

Studi Francesi è distribuita con Licenza Creative Commons Attribuzione - Non commerciale - Non opere derivate 4.0 Internazionale. 


\title{
Honoré de Balzac, Albert Savarus
}

\author{
Marco Stupazzoni
}

\section{NOTIZIA}

Honoré de Balzac, Albert Savarus, a cura di P. Pellini, trad. di F. Monciatti, Palermo, Sellerio, 2017, «La memoria» 1063, 231 pp.

1 Pubblicato prima in appendice ne "Le Siècle" (29 maggio-11 giugno) e immediatamente inserito nel primo volume de La Comédie humaine di Furne il 25 giugno 1842, Albert Savarus vede per la prima volta (e finalmente) la luce in volume tradotto con rigore da Francesco Monciatti, in questa bella edizione curata da Perluigi Pellini per la collana «La memoria» dell'editore Sellerio.

2 Si tratta, come abbiamo riferito, della prima traduzione italiana pubblicata in volume, ma non della prima versione del romanzo in senso assoluto apparsa in Italia: una nostra recente trouvaille ha permesso, infatti, di individuare, tra le pagine del quotidiano "Il Giornale di Padova", quella che, verosimilmente, può considerarsi come la prima traduzione del romanzo balzachiano nel nostro idioma. Pubblicata a puntate dal 17 maggio al 20 giugno 1881, essa ha come titolo Gloria Mundi e, lontana dal potersi ritenere esemplare per aderenza e fedeltà al modello francese, si deve a Ugolino Ugolini.

3 Il 1842 è un anno determinante nella vita di Balzac per quanto concerne, soprattutto, il coinvolgimento sentimentale del romanziere con Mme Hanska e il suo tentativo di ricucire un legame ormai prossimo al logoramento. In questa strategia di riconquista, osserva P. Pellini nella sua ottima postfazione al romanzo ( “desiderio"», pp. 201-225), «si inserisce - tassello fondamentale quanto ambiguo - la scrittura di Albert Savarus» (p. 204). Il libro, infatti, non sarà, come scrive Balzac alla Straniera, una lezione per l'uomo, ma essenzialmente una lezione per Mme Hanska. L'azione di Albert Savarus si svolge in provincia, a Besançon (luogo di stendhaliana memoria), in un contesto ristretto e opprimente, ben lontano dal dinamismo proprio degli scenari parigini. Il testo, nel quale risulta evidente l'allusività autobiografica, 
rivela, al di là delle finalità contingenti (la riconciliazione con Mme Hanska), una «inopinata complessità metaletteraria» (p. 210), motivo non ultimo della sua ricchezza e del suo fascino. In Albert Savarus, Balzac afferma il valore in sé del desiderio (indipendentemente dal risultato) postulando, allo stesso tempo, «la sua coincidenza con l'immaginazione romanzesca» (p. 217). Questa mistica del desiderio trova, nel romanzo, il suo punto focale non tanto o non solo nei personaggi maschili, ma soprattutto in una figura femminile, quella di Rosalie: il suo peso diegetico nell'economia della narrazione la eleva a vero e unico personaggio romanzesco proprio perché il «motore della trama è la violenza umanissima e incommensurabile, in tutti i sensi incontrollabile, del suo desiderio» (p.222). A questo genio del male, Balzac riconosce simbolicamente «un accesso privilegiato a quelle sorgenti dell'energia e del desiderio che più di ogni altra cosa determinano [...] la grandezza degli umani destini» (p. 225). 